\title{
Experiment and Analysis of Concrete Superimposed Beam-plate under Secondary Load
}

\author{
Limin Yang ${ }^{1, a}$, Jiangwei Wang ${ }^{1, b}$ and Jinjun Guo ${ }^{2, c^{*}}$ \\ 1. China Construction Seventh Engineering Division, Zhengzhou 450003, China; \\ ${ }^{2}$ School of Water Conservancy \& Environment Engineering, Zhengzhou University, Zhengzhou \\ 450001, China \\ ayanglm777@sina.com, b1688wjw@163.com, cguojinjun@zzu.edu.cn
}

Keywords: concrete, superimposed beam-plate, secondary load, strengthening

Abstract. Combining with strengthening engineering of a practical reinforced concrete plate bridge serving for 30 years, the superimposed experiments of four old bridge plates were studied with full size of $4960 \mathrm{~mm}^{*} 950 \mathrm{~mm} * 220 \mathrm{~mm}$. The characteristics of composite members under secondary load stage were analyzed, such as load prestress, bilinear distribution of strain, tensile stress excess of reinforcement and compressive strain lag. Based on experiments and analysis, the calculation formulas of rebar stress control, the characteristic coefficient $\beta$ and short-term stiffness of composite members were deduced. By comparison, the proposed formulas results coincide well with test data and are closer to test values than those from Code formulas. The bearing capacity of superimposed beam-plate increases 2.3 times higher than original plate. The strengthened bridge using this method has served more than 5 years, which shows that composited strengthening method of bridge plate is economically feasible.

\section{Project Overview}

A reinforced concrete simply supported bridge was built in June, 1980. Total length of the bridge was $75 \mathrm{~m}$ and net width was $3.6 \mathrm{~m}$ with 15 holes. Each hole was constructed by 4 rectangular solid RC precast beam-plates. The beam-plate in size of $4960 \mathrm{~mm} * 950 \mathrm{~mm} * 220 \mathrm{~mm}$ was directly supported on piers. The design strength of concrete was $13 \mathrm{MPa}$ and reinforcement bar strength was $210 \mathrm{MPa}$.

The design vehicle load of the bridge was grade six. Several cracks and some degree carbonization were appeared on the surface of slab bottom. Considering cost and shorting construction time, the bridge was strengthened by superimposing new concrete because original design function couldn't meet demand due to the rapid development of urban and rural economy and the increasing of vehicle flow and vehicle tonnage.

\section{Test Survey}

Four old panels removed from the bridge were transported to the laboratory. Surfaces of the plates were treated in four different ways before bonded. S1 was smooth clean plane which was brushed up and washed out; S2 was artificially chiseled groove surface with $150 \mathrm{~mm}$ interval along longitudinal direction. The average width of the upper groove was about 30mm, the average depth was about $4 \mathrm{~mm}$, the chiseling ratio of area was $20 \%$; S3 was treated with the same way as S2, but the spacing of chiseled groove was $100 \mathrm{~mm}$, the chiseling ratio was 30\%; S4 was embedded surface with composited rebar $\varphi 10$. The embedded depth of rebar was $70 \mathrm{~mm}$ and the exposed length were $120 \mathrm{~mm}$ while the rate of composited rebar was $0.87 \%$.

Considering the actual situation of strengthening construction, simply supported on both ends style was adopted. The old precast plate was treated as bottom die while casting concrete of composite layer. The thickness of new pouring concrete was $200 \mathrm{~mm}$, design strength was $20 \mathrm{MPa}$. For simulating actual load of rear wheel on bridge deck, uniform load was applied on the area of $200 \mathrm{~mm} * 500 \mathrm{~mm}$ at mid-span ${ }^{[1]}$. The test contents of the composite plate mainly included: load capacity, deflection, concrete strain, crack ,etc. The schematic diagram of superimposed beam-plate was showed in Fig.1. 


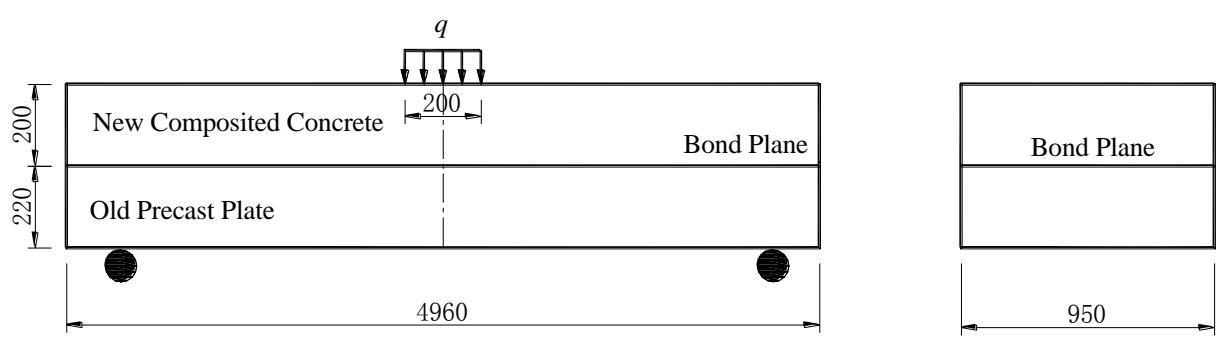

Fig.1 The schematic diagram of superimposed beam-plate (Unit:mm)

\section{Characteristics of Secondary Loaded Composite Beam-plate}

Load Prestress. At strengthening stage, the stress existed in the precast plate under deadweight of precast plate and composite layer while no stress emerged in composite layer. The stress produced by first stage load was called load prestress ${ }^{[2]}$. The concrete compressive stress above the neutral axis of precast slab was called load comperssive prestress and tensile stress under the neutral axis called load tensile prestress, while the strain corresponding prestress was called load prestrain. Moment ratio of the precast slab was $M_{1} / M_{u 1}=16 \%$. $\left(\mathrm{M}_{1}\right.$ was the moment produced by first stage load in precast slab, $\mathrm{M}_{\mathrm{u} 2}$ was the ultimate moment of precast slab).

Bilinear Distribution of Section Strain. The actual strain of the superimposed beam-plate section was different from one-time casted plate because of load prestrain, shown in Fig. 2. The strain in the superimpose beam-plate could be treated as bilinear approximately and the strain jumped at the bond plane. The upper zone of composite part was under compression and the other concrete was subjected to tension. The upper concrete of precast slab was compressed while the lower part was tensile. The regularity of strain distribution didn't change until the crack passed through the bond plane.

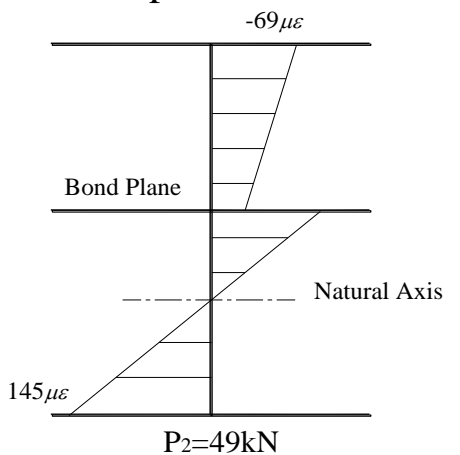

Fig.2 The distribution graph of section strain

The Tensile Stress Excess of Reinforcement in the Superimposed Slab. For superimposed beam-plate, the tensile stress of reinforcement existed in original plate existed before the secondary load was applied. This stress was called as stress excess compared to one-time casted plate. The stress excess should be controlled in design because it could result in reinforcement yielding earlier and crack width increasing. According to test data and results of finite element analysis, the value of stress excess had a little change during the secondary load stage.

The Compressive Strain Lag of Superimposed Concrete. For superimposed beam-plate, the section moment $\mathrm{M}_{1}$ caused by deadweight or first stage load acted on the section of original element, but strain of late poured concrete was zero. This was called as compressive strain lag. This phenomenon caused bigger compression area and increased the compressive property of superimposed concrete. So the ultimate bearing capacity of superimposed member was no less than integral casted plate. Based on test and finite element analysis, the compressive strain lag would keep even after reinforcement yielding. In this experiment, the concrete compressive strain was only $360 \sim 570 \mu \varepsilon$ when reinforcement yielding. 


\section{Secondary Load Analys is of Superimposed Beam-plate}

Stress Control of Reinforcement. Based on test data and finite element analysis, the stress condition of cross-section was shown in fig. 3. The following assumptions are proposed.
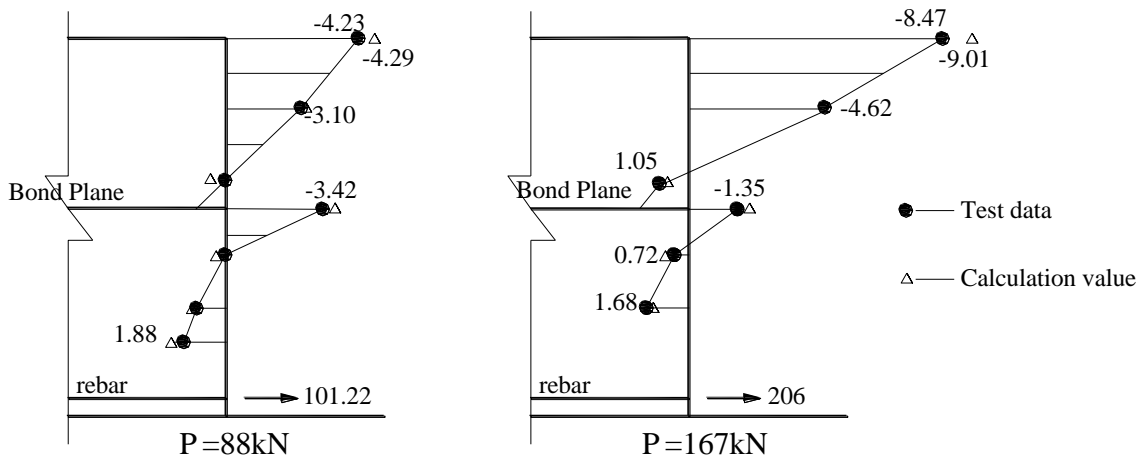

Fig.3 The graph of section stress

(1) Plane section assumption ${ }^{[3-4]}$;

(2) The maximum value of reinforcement stress induced by first stage load is unchanged;

(3) Concrete in compressive area is in elastic state;

(4) Ignore tensile effect of concrete in tensile area

Let $A \mathrm{~s}, h_{01}, \rho_{1}, \eta_{1}$ respectively be rebar area , the effective height, reinforcement ratio, internal force arm coefficient of original plate under the first stage load. Let $h_{0}, \rho, \eta_{2}$ respectively be the effective height, reinforcement ratio, internal force arm coefficient of the superimposed beam-plate under secondary load. $\alpha_{\mathrm{E} 1}$ is the elastic modules ratio of reinforcement and the concrete for precast plate while $\alpha_{\mathrm{E}}$ is the elastic modules ratio of reinforcement and the post-pouring concrete.

The steel stress caused by the first stage load, $\sigma_{\mathrm{s} 1}$, was given by:

$$
\begin{aligned}
& \sigma_{s 1}=\frac{M_{1}}{\eta_{1} A_{s} h_{01}} \\
& \eta_{1}=1-\frac{1}{3}\left[\sqrt{\left(\rho_{1} \alpha_{E 1}+1\right)^{2}}-\rho_{1} \alpha_{E 1}\right]
\end{aligned}
$$

The steel stress $\sigma_{\mathrm{s} 2}$ caused by the secondary load $\mathrm{M}_{2}$ was given by:

$$
\begin{aligned}
& \sigma_{s 2}=\frac{M_{2}(1-\beta)}{\eta_{2} h_{0} A_{s}} \\
& \eta_{2}=\frac{1}{3}\left[\sqrt{(\omega+1)^{2}-1}-\omega\right] \\
& \omega=\frac{\alpha_{E} \rho \xi_{s}}{\xi_{s}-\xi_{s 1}}, \quad \xi_{s 1}=\frac{\sigma_{s 1}}{f_{y}}, \quad \xi_{s}=\frac{\sigma_{s}}{f_{y}}
\end{aligned}
$$

Characteristic coefficient of secondary load ${ }^{[5]}, \beta$, was given by:

$$
\beta=\frac{M_{1}}{M_{2}}\left(\frac{\eta_{2} h_{0}}{\eta_{1} h_{01}}-1\right)
$$

Calculation showed that the internal force arm coefficient $\eta_{1}$ was almost equal to $\eta_{2}$, so approximately make $\eta_{1} / \eta_{2}=1$, 


$$
\beta=\frac{M_{1}}{M_{2}}\left(\frac{h_{0}}{h_{01}}-1\right)
$$

The stress control formula of longitudinal reinforcement was given by:

$$
\sigma_{s}=\sigma_{s 1}+\sigma_{s 2} \leq 0.9 f_{y}
$$

The formula (1) had the same computation expression with Code for Design of Concrete Structures (GB50010-2010)(Chinese), but the derivations were different. $\eta_{1}$ and $\eta_{2}$ was taken 0.87 directly in Code, but the formula (2) and (4) were not given in Code.

According to the data from literature [6], the calculating comparison of $\beta$ between the Code formula and the formula (7) suggested in this paper were listed in Tab.1. For superimposed members with $M_{1} / M_{2} \leq 40 \%$, the deduced formula in this paper presented well the variation of $\beta$ and coincided well with the test values. Compared the formula calculation results with experimental data, the average was 1.018 , the coefficient of variation was 0.173 , while the average was 0.883 and the coefficient of variation was 0.462 by comparing the code results with experimental data.

Tab.1 Comparison of $\beta$

\begin{tabular}{ccccccccc}
\hline $\begin{array}{c}b \times h \\
(\mathrm{~mm} \times \mathrm{mm})\end{array}$ & $\frac{h_{1}}{h}$ & $\frac{h_{01}}{h_{0}}$ & $\begin{array}{c}M_{1} \\
(\mathrm{KN} . \mathrm{m})\end{array}$ & $\begin{array}{c}M_{2} \\
(\mathrm{KN} . \mathrm{m})\end{array}$ & $\begin{array}{c}M_{1} \\
M_{2}\end{array}$ & $\begin{array}{c}\beta \\
(\text { Code })\end{array}$ & $\beta$ (Article) & $\beta$ (Test) \\
\hline $144 \times 445$ & 0.306 & 0.278 & 2.77 & 65.00 & $4.3 \%$ & 0.35 & 0.11 & 0.11 \\
$150 \times 444$ & 0.318 & 0.285 & 7.93 & 53.60 & $14.8 \%$ & 0.34 & 0.37 & 0.37 \\
$150 \times 350$ & 0.400 & 0.366 & 2.76 & 30.39 & $9.1 \%$ & 0.30 & 0.16 & 0.11 \\
$150 \times 453$ & 0.280 & 0.247 & 6.75 & 75.97 & $8.9 \%$ & 0.36 & 0.27 & 0.30 \\
$150 \times 348$ & 0.402 & 0.366 & 2.76 & 38.60 & $7.1 \%$ & 0.30 & 0.12 & 0.11 \\
$150 \times 347$ & 0.403 & 0.367 & 5.59 & 25.56 & $21.9 \%$ & 0.30 & 0.32 & 0.35 \\
$150 \times 352$ & 0.398 & 0.361 & 5.58 & 31.46 & $17.7 \%$ & 0.30 & 0.31 & 0.35 \\
$148 \times 358$ & 0.397 & 0.356 & 6.63 & 28.50 & $23.3 \%$ & 0.30 & 0.42 & 0.40 \\
$150 \times 350$ & 0.414 & 0.379 & 7.06 & 28.10 & $25.1 \%$ & 0.29 & 0.41 & 0.40 \\
$149 \times 310$ & 0.442 & 0.405 & 2.27 & 30.55 & $7.4 \%$ & 0.28 & 0.11 & 0.11 \\
$150 \times 308$ & 0.555 & 0.523 & 2.85 & 33.34 & $8.5 \%$ & 0.22 & 0.08 & 0.12 \\
$150 \times 304$ & 0.550 & 0.518 & 7.21 & 22.66 & $31.8 \%$ & 0.23 & 0.30 & 0.27 \\
$150 \times 307$ & 0.537 & 0.509 & 7.18 & 21.63 & $33.2 \%$ & 0.23 & 0.32 & 0.31 \\
$150 \times 303$ & 0.548 & 0.518 & 9.86 & 13.02 & $75.7 \%$ & 0.23 & 0.66 & 0.35 \\
$149 \times 311$ & 0.518 & 0.486 & 9.96 & 14.78 & $67.4 \%$ & 0.24 & 0.62 & 0.40 \\
\hline
\end{tabular}

The Short-term Stiffness for Superimposed Member. Under serviceability limit state, concrete of compressive area stayed low-pressure state when reinforcement yielded. The stress of compressive area concrete could be expressed as triangle distribution quite accurately. Therefore, the formula of short-term stiffness of superimposed member under the secondary load stage was derived by:

$$
B_{s 2}=\frac{E_{s} A_{s} h_{0}^{2}}{1.11 \psi \frac{M_{2}}{M}(1-\beta)+7.41 \alpha_{E} \rho}
$$

where $\psi$ is the uneven coefficient of reinforcement strain between cracks, which is taken from the Code.

The results comparison between formula (8) and Code are given in tab.2. $f_{2}$ is deflection of midspan of superimposed beam-plate under secondary load. 
Tab.2 Comparison of $B_{\mathrm{s} 2}$ and deflection

\begin{tabular}{|c|c|c|c|c|c|c|c|c|}
\hline \multirow{2}{*}{$\begin{array}{c}M_{2} \\
(\mathrm{kN} \cdot \mathrm{m})\end{array}$} & \multirow[b]{2}{*}{$\frac{M_{1}}{M_{2}}$} & \multirow[b]{2}{*}{$\beta$} & \multirow[b]{2}{*}{$\varphi$} & \multicolumn{2}{|c|}{ Code } & \multicolumn{2}{|c|}{ Article } & \multirow{2}{*}{$\begin{array}{c}\text { Test } \\
f_{2} \\
(\mathrm{~mm})\end{array}$} \\
\hline & & & & $\begin{array}{c}B_{\mathrm{s} 2} \\
2 \\
\left(\mathrm{~N} \cdot \mathrm{mm}^{2}\right) \\
\end{array}$ & $\begin{array}{c}f_{2} \\
(\mathrm{~mm})\end{array}$ & $\begin{array}{c}B_{\mathrm{s} 2} \\
2 \\
(\mathrm{~N} \cdot \mathrm{mm})\end{array}$ & $\begin{array}{c}f_{2} \\
(\mathrm{~mm})\end{array}$ & \\
\hline 100 & 0.1917 & 0.2023 & 0.5136 & $6.550 \times 10^{13}$ & 2.10 & $10.87 \times 10^{13}$ & 1.26 & 1.33 \\
\hline 150 & 0.1314 & 0.1349 & 0.6850 & $6.550 \times 10^{13}$ & 3.13 & $8.565 \times 10^{13}$ & 2.39 & 2.34 \\
\hline 200 & 0.0986 & 0.1010 & 0.7788 & $6.550 \times 10^{13}$ & 4.17 & $7.561 \times 10^{13}$ & 3.62 & 3.68 \\
\hline 230 & 0.0857 & 0.0880 & 0.8172 & $6.550 \times 10^{13}$ & 4.67 & $7.196 \times 10^{13}$ & 4.37 & 4.47 \\
\hline $250 *$ & 0.0788 & 0.0810 & 0.8285 & $6.550 \times 10^{13}$ & 5.09 & $6.660 \times 10^{13}$ & 5.13 & 5.35 \\
\hline
\end{tabular}

Note: * means reinforcement yields.

Calculation shows that the calculation results of formula suggested in this paper have good coincidence with experimental data. When reinforcement yields, the calculation error starts to enlarge because the stress of compressive concrete no more keeps triangle distribution. However, it is no significance to calculate the deflection of component after reinforcement yielding. Compared with formula of paper, the short-term stiffness in the code is a constant which is quite unreasonable obviously. The formula in this paper reflects the influences of $\beta$ and $\mathrm{M}_{2} / \mathrm{M}$ or $\mathrm{M}_{1} / \mathrm{M}$ on stiffness.

Calculation Results. Based on the superimposed beam-plate in this test, the formulas for the bearing capacity of normal section and crack width were also put forward.

The results show that: the bearing capacity of the superimposed beam-plate is 3.13 times higher than the original precast plate according to normal section strength; for rebar stress control, it is 2.31 times; for crack width checking it is 1.61 times; for deflection calculation, it is 3.68 times. Summing up, maximum wheel load of the superimposed beam-plate is $68.9 \mathrm{kN}$ in normal use, while the maximum wheel load of old precast plate is $29.8 \mathrm{KN}$. So, the load capacity of bridge improves 2.3 times by means of superimposing reinforcement.

\section{Conclusions}

(1) The strengthening method of compositing new on old concrete is totally feasible, which not only increases the bearing capacity of structure but saves a mass of fund and construction time.

(2) It is the first time to deduce the calculating formula of rebar stress control, characteristic coefficient $\beta$ and short-term stiffness of superimposed member under secondary load stage. Compared to the formula in Code, results of the proposed formula are closer to experimental results.

(3) The bearing capacity of bridge increases 2.3 times higher than the original bridge after composited strengthening.

\section{References}

[1] General Code for design of Highway Bridges and Culverts (JTG D60-2004), China Communications Press, Beijing, 2004.

[2] Gohnert M. Horizontal shear transfer across a roughened surface, Cem. Concr. Compos. , 25( 2003) 379-385.

[3] Y.J. Yang, W.C. Xue, Experimental study on the static behavior of reinforced concrete composite T-beams. China Civil Eng. J., 43(2010) 1-7.

[4] Lawrence F K, Adam S. Interface shear in high strength composite T-beams. PCI J. , 49( 2004 )102-110.

[5] Code for design of concrete structures (GB 50010-2010), China Architecture \& Building Press, Beijing, 2011.

[6] S.Y. Li, S.B. Zhao, Y.X. Wang, Experimental research on the mechanical properties of reinforced concrete composite beam, J. Hydroelectric Eng., 13 ( 1994) 37-47. 